\title{
Synchronous Distance Education: Using Web-Conferencing In An MBA Accounting Course
}

Dee Ann Ellingson, University of North Dakota, USA Matthew Notbohm, University of North Dakota, USA

\begin{abstract}
Online distance education can take many forms, from a correspondence course with materials online to fully synchronous, live instruction. This paper describes a fully synchronous, live format using web-conferencing. Some useful features of web-conferencing and the way they are employed in this course are described. Instructor observations and perceived benefits are presented, along with some challenges.
\end{abstract}

Keywords: Distance Education; Web-Conferencing; Synchronous Instruction

\section{INTRODUCTION}

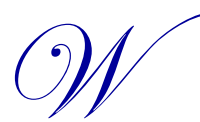

hile distance education has existed for many years, technology has led to an explosion in online and other distance education formats. Online distance education methods can vary greatly, from a correspondence course with materials accessible online to fully interactive live instruction, with many variations in between (Bernard et. al., 2008; Roblyer et. al., 2007).

This paper describes the use of web-conferencing as a platform for an MBA accounting course. This course has been delivered to distance learners in a fully synchronous, live format since the mid-1990s, initially using interactive video network (IVN) in which students in a remote classroom were connected to the instructor and main classroom through video and microphone. Web-conferencing was introduced in 2008. With web-conferencing, each distance student is at a computer with camera and microphone in disparate locations instead of sitting in a remote classroom. At that time, distance students and campus students were in separate sections of the course. Beginning in 2010, a "hybrid"1 format was adopted in which distance students and campus students receive instruction at the same time, with the distance students logged in to the course site and the campus students and instructor in the classroom.

In the next section, the features of web-conferencing are described, along with examples of the course site. Instructor observations and student feedback are discussed in the following section.

\section{FEATURES}

Many web-conferencing choices are available, each with their own features. Free services, such as Skype, are accessible for small groups or one-on-one instruction (Karabulut and Correia, 2008). Many 'pay services' are available which can accommodate group sizes from 15 to 1,000 attendees, such as WebEx, GoToMeeting, and Adobe Connect. (Visit http://web-conferencing-services.toptenreviews.com/ for a comparison.) Some course management systems now offer web-conferencing, such as Wimba Classroom in Blackboard. Although a number of

\footnotetext{
${ }^{1}$ Terms may have different meanings with respect to distance education. For example, the "hybrid" approach here is called a "blended environment" by Armstrong et. al. (2007) while Jackson and Helms (2008) use "hybrid" to refer to a format "balancing traditional face-to-face classroom instruction with online components."
} 
products offer similar features, this paper describes only those features, in Adobe Connect, more commonly used in this course.

Web-conferencing allows students to interact live with the instructor and other students via camera and microphone and also through a chat (messaging) box. The course site has a unique URL which students are provided prior to the beginning of instruction. Students and instructor login into the course site. Guests may log in as a guest, but must be approved by the instructor. Once in the course site, the instructor may select one of two views - Main Class View or Q\&A View - which sets the view for all participants.

Exhibit 1 displays the course site in Main Class View. The course site consists of several boxes or "pods," including (from upper left) Camera and Voice pod, Attendee List pod, Student Questions pod, and Share pod. Pods can be hidden or sized by the instructor. The instructor and students can see each other live in the Camera and Voice pod. Since this was a "hybrid" course with both distance and campus students, a separate camera was used to allow the distance students to see the campus students (see the thumbnail labeled "Classroom" in Exhibit 1), and microphones in the classroom allow distance students to hear campus students. In the classroom, the course site was projected onto the screen for the campus students. The example in Exhibit 1 is from a Fall 2010 class which was taught in a "hybrid" format with 13 distance students and 16 campus students at the same time. Distance students that semester were in locations from Tennessee to North Dakota to Nevada.

Exhibit 1: Course Site in Main Class View

(Last names removed and faces obscured. Some students did not have their cameras on.)

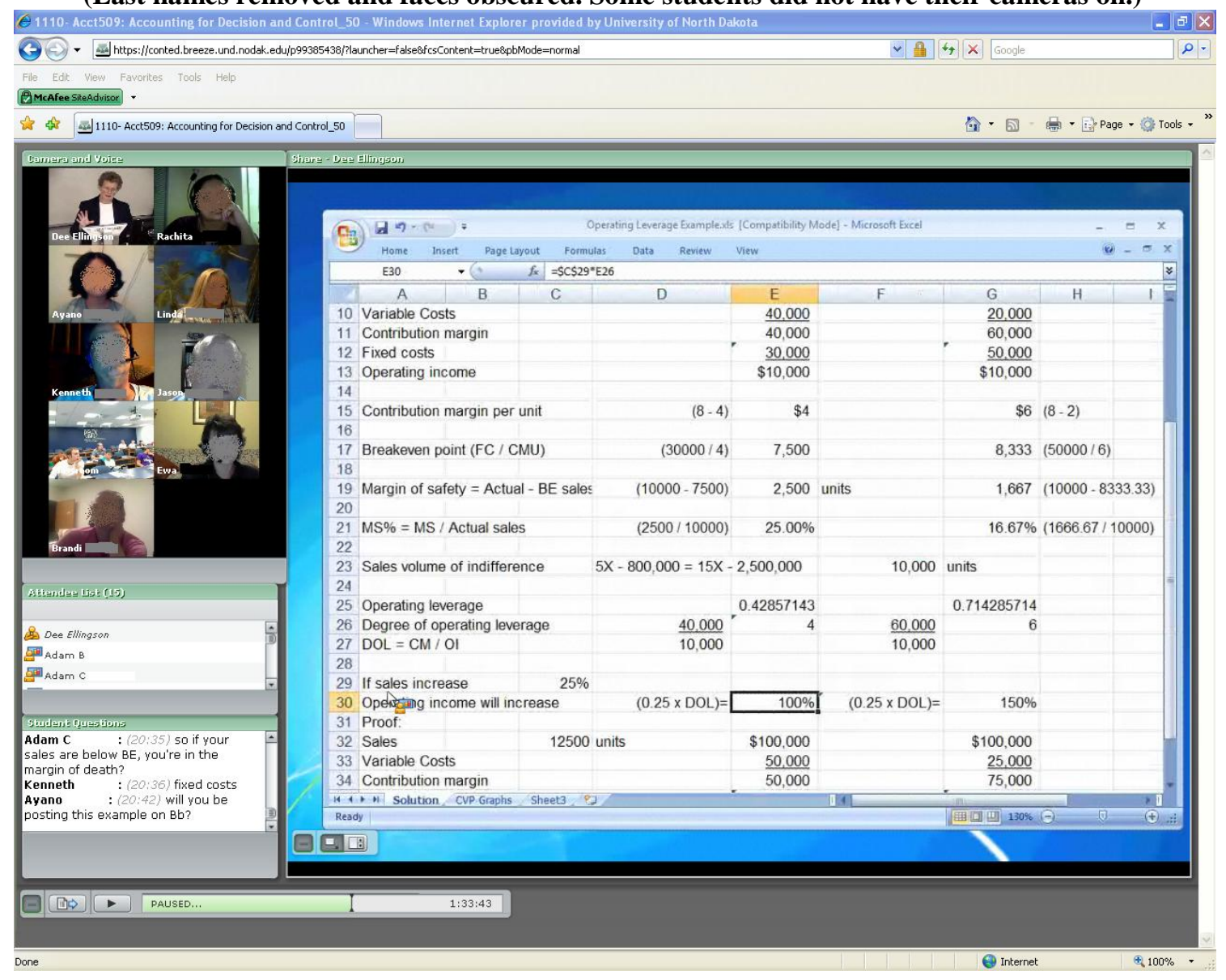


The Attendee List pod shows all participants logged into the course. Participants can use several icons to convey a message in this pod, such as "raising their hand", although they seldom do. Instead, the students tended to use the Student Questions pod, which acts as a chat or instant messaging feature that allows participants to ask or answer questions or make comments. Messages may be sent to everyone or privately to the instructor or another participant.

In the Share pod, course materials are displayed for lecture or discussion, which may include presentation slides, websites, or documents such as Word, Excel, or a pdf. There is also a whiteboard feature in the share pod that can be used for illustrations, examples, etc. With dual monitors, the instructor can share materials displayed on the second monitor with the class. Alternatively, documents may be uploaded in advance.

When no materials are being shared, switching to Q \& A View enlarges the Camera and Voice, Attendee List, and Student Questions pods to allow for class discussion or question and answer sessions. See Exhibit 2 for an example of the course site in Q\&A View.

Exhibit 2: Course Site In Q\&A View

Three pods are visible: Attendee List, Camera and Voice, and Student Questions

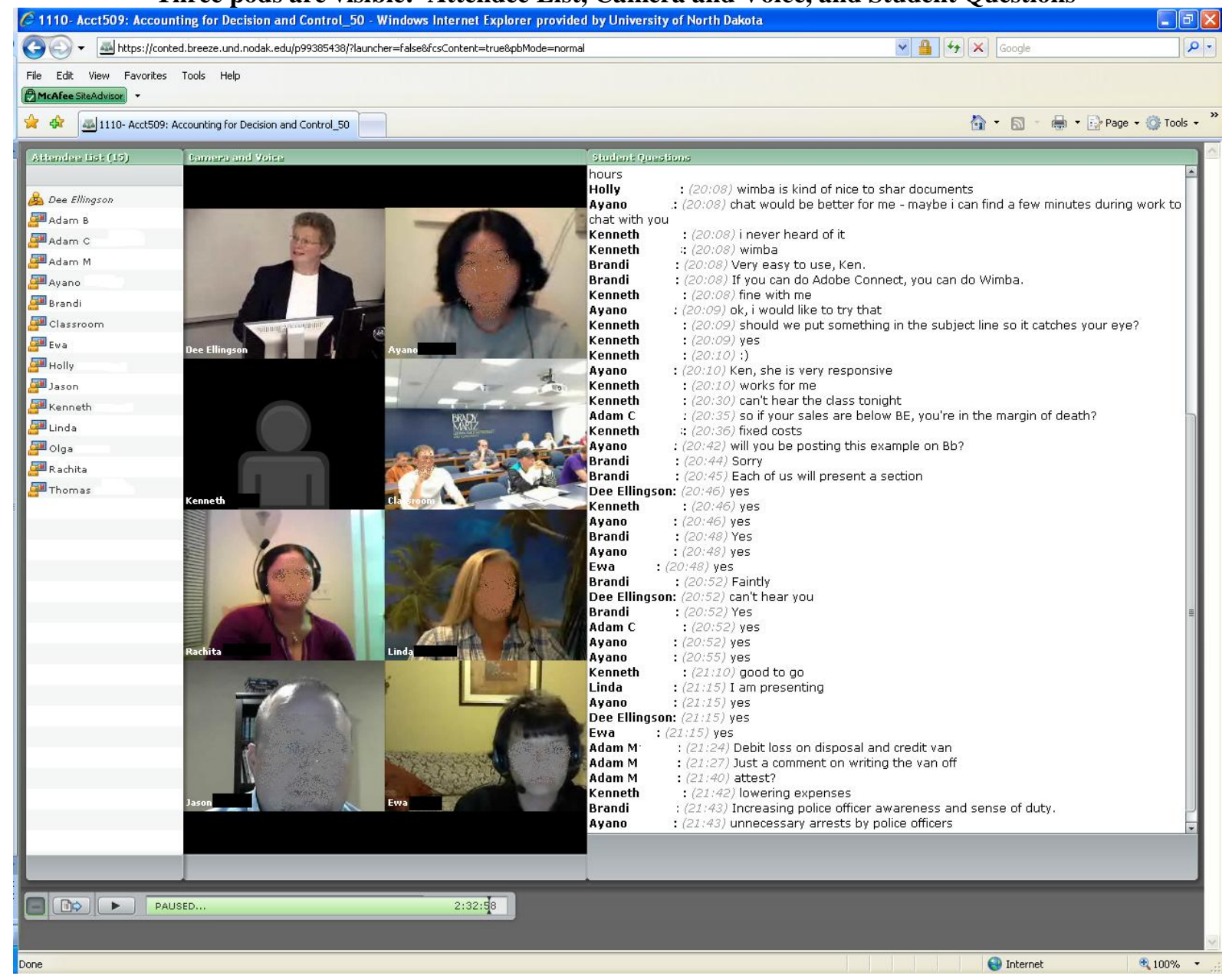


Distance students may participate in the discussion by raising their hand (an icon appears next to their name in the Attendee List pod) or sending a chat message within the Student Questions pod. The instructor can then call on the student to turn on their microphone and share with the class. It works best to have one or maybe two microphones on at a time, unless it's a small group in a breakout room (discussed below). Rather than turning on their microphone, many students just send their question or comment in a chat message in the Student Questions pod. Since many are familiar with texting, students are comfortable using the Student Questions pod to communicate, and distance students seem more inclined to ask questions than their campus counterparts because they don't have to interrupt the instructor. This also aids the instructor who can finish a thought or comment before addressing the student's question.

Another useful feature is the breakout rooms, which allow distance students to engage in small group discussion during class. Exhibit 3 shows the course site with the breakout rooms.

Exhibit 3: Course Site With Breakout Rooms

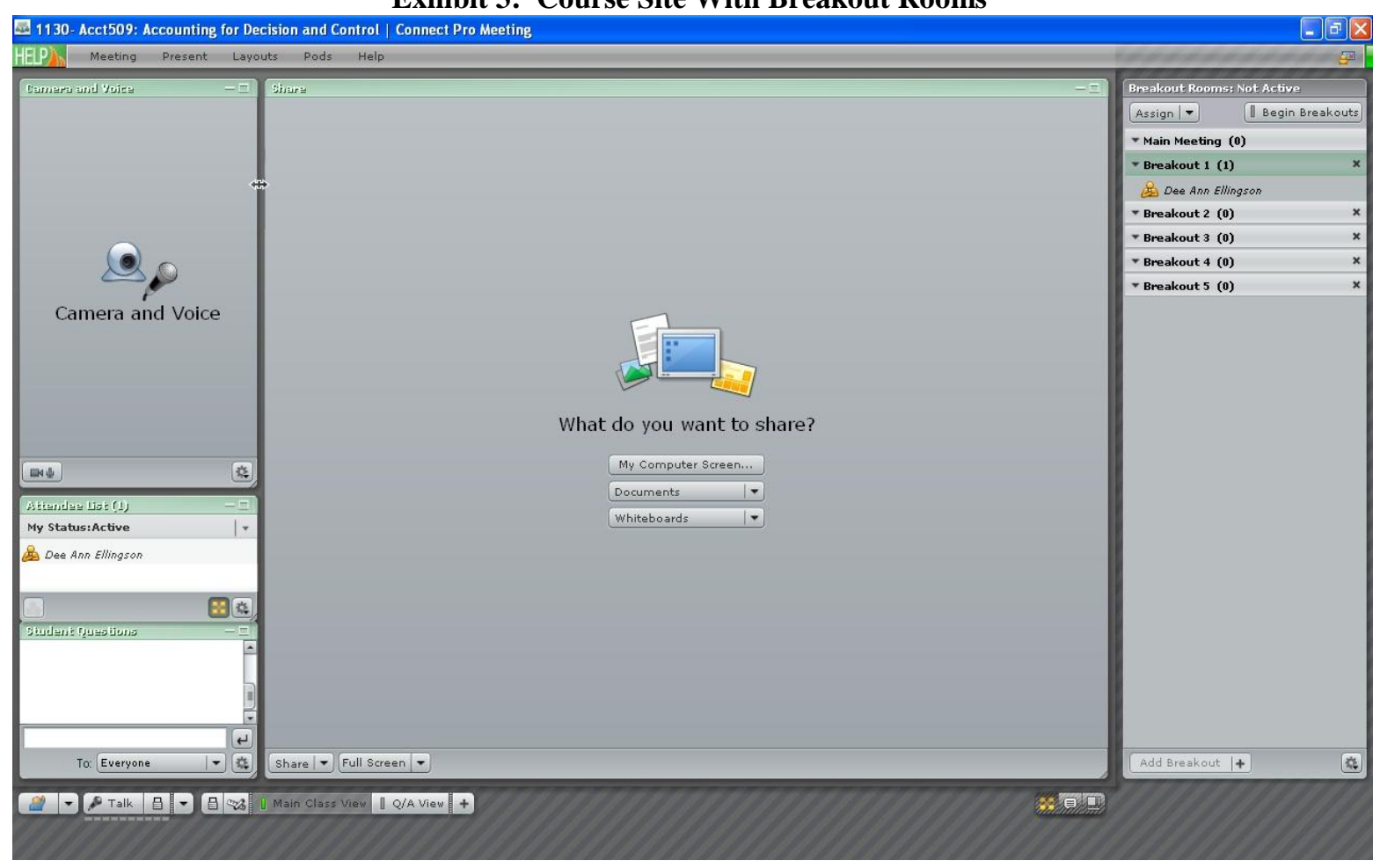

The instructor assigns participants to each breakout room and then clicks on "Begin breakouts" to activate them. When the breakouts are active, the distance students can see and talk to only the students in their small group. The instructor can easily visit each breakout room to listen or contribute to the discussion. Students know if the instructor joins them in their breakout room because their name will appear in the Attendee List pod, which shows only the participants in the breakout room when the breakouts are active.

Many of these features have been used to make the class very interactive. In this class, both distance and campus students are assigned to groups of ideally three students, although groups or two or four have been used when necessary. Each week, each group is responsible to develop a solution to one of the assigned homework problems using the wiki feature in Blackboard. At the beginning of class, the breakout rooms are used to allow the students to discuss their solution and decide which group member will present it. A member of the group's choosing then presents their group's solution in class. The group's Blackboard wiki solution is displayed in the Share pod and a distance student turns on their camera and microphone to present while a campus student uses the instructor's station in the front of the classroom. A distance student can request control of the screen which, when granted by the instructor, allows the student to navigate through their presentation. 
The recording feature is also very useful. The instructor can turn on the recording feature and capture the class in its entirety or portions of it. In this class, each session was recorded and posted on Blackboard after the meeting was completed. Students appreciate this feature when they have to miss class due to illness or traveling for work and can later watch the recording. The recording feature has also been used by the instructor to pre-record a lecture for a different campus class prior to going out of town.

\section{OBSERVATIONS AND FEEDBACK}

Informal feedback from the distance students on the web-conferencing format has been very positive. They appreciate the live instruction and ability to interact with each other and with the instructor. Student views are mixed on the "hybrid" format of combining distance and campus students into one class. Some distance students appreciate the effort to connect them with the campus community. Others are not so enamored with it. While the goal of joining campus and distance students in one community is laudable, campus students complain that it slows the class down while distance students sometimes feel overlooked or left out.

One might wonder if distance students are motivated to attend classes via web-conferencing, especially given that sessions are recorded and posted. In our experience, attendance by distance students is as good as, or even better than, campus students. The distance students rarely miss class and most often will notify the instructor when they need to do so.

\section{BENEFITS AND CHALLENGES}

Anecdotal evidence seems to suggest there are a number of benefits to using web-conferencing in distance education. For the students, these include increased motivation, preparation, and participation; collaboration and community-building; use of technology; and convenience. Benefits for the instructor and university include access to remote students and alternative platforms for delivery of instruction.

\section{Motivation, Preparation and Participation}

Live instruction via web-conferencing encourages students to become more engaged in the course than if asynchronous, non-interactive methods are used. Weekly live class meetings encourage regular attendance and motivate students to keep up with material and prepare for class. Group discussions and presentations promote participation and hold students accountable to their peers as well as the instructor.

\section{Collaboration and Community-building}

Enabling students to see and hear one another builds inter-personal relationships and promotes peer-to-peer learning. Although group work may be accomplished through other means, web-conferencing allows students to "meet" face-to-face. Live instruction via web-conferencing pulls the distance students into a community so they are less likely to feel alone and isolated. The "hybrid" format brings distance and campus students into a shared experience and connects the distance students with the university.

\section{Use of Technology}

Many students are comfortable with technology and quickly learn to use the web-conferencing software. This exposes them to additional tools they may use in their continued education and in their professional careers.

\section{Convenience}

The live interactive features of web-conferencing have attracted distance students who prefer synchronous instruction over other asynchronous forms of distance education. With minimal equipment (computer, camera, microphone, internet connection), a student can attend class from any location. Students have sometimes attended class when out of town for work and, on occasion, campus students have asked special permission to attend online when feeling ill so they would not have come to the classroom. On one occasion when there was a winter storm 
warning the evening before Thanksgiving, distance and campus students, as well as the instructor, all held class on the course site from their safe, warm locations.

\section{Benefits for University and Instructor}

Distance education, in general, allows more students to access education, leading to higher enrollments for the university without the demand for physical facilities. The added benefit of using web-conferencing allows a program to attract students who prefer live instruction over asynchronous forms but who are unable or unwilling to physically come to campus. This widens the pool of potential students who may enroll at the university.

For the instructor, this technology can be used in many creative ways in addition to regular class meetings. For example, the course site has been used to bring in a guest speaker from a remote location. This was done in a distance class, but could also be used in a traditional classroom to bring in a guest speaker without requiring them to come to campus. The course site can be used to pre-record a lecture when the instructor must miss class or to record an example or illustration of a concept the students are having difficulty with. Recordings may be posted on a class management site like Blackboard. The course site can also be used to meet with students one-on-one or in small groups for office hours or help sessions. The instructor may also benefit from the convenience. For distance-only sections, the instructor has taught the class from home due to commuting issues.

Along with the benefits come a number of challenges, including faculty investment, technology limitations, and technical problems.

\section{Faculty Investment}

One of the biggest challenges is the investment by the faculty member in learning the technology. Many universities provide resources, such as workshops and assistance in instructional design, but it often comes down to good old trial and error, finding what works best for the individual faculty member's teaching style and course requirements. Some aspects of an instructor's teaching style may need to be adapted for web-conferencing. For example, mobility is limited by the camera angle, so an instructor who moves around a lot would need to adjust accordingly, or a faculty member who makes extensive use of a document camera or chalkboard would need to adapt by uploading documents in advance or use the whiteboard in the course site.

In addition to learning the technology, a faculty member needs to learn how to manage the class in a new environment. For example, a transition from lecture to small group discussion is more complicated in the webconferencing site than it would be in a traditional classroom. The hybrid approach poses the additional challenge of blending the traditional classroom and distance environments so that one group does not feel left out or overlooked.

\section{Technology Limitations}

Although the web-conferencing software could allow more participants, the class size is limited to 20 distance students due to bandwidth constraints. Additionally, it usually works best to have one microphone on at a time, unless there is a small group. For example, when small groups are meeting privately in their breakout rooms, all participants can have their microphones on with no problems. For the hybrid class, the classroom is equipped with microphones to allow distance students to hear campus students. Too much background noise, however, can sometimes be distracting to both students and instructor.

\section{Technical Problems}

As with any technology-dependent venture, technical problems may arise. When technical problems occur, troubleshooting can be difficult and time-consuming. Since campus students are not dependent on the technology, they can become impatient when technical problems occur. Fortunately, problems occurred infrequently and our university provides excellent support, which may not be the case at all schools. 


\section{CONCLUSION}

Online distance education can take many forms. This paper describes a fully synchronous approach to distance education using web-conferencing. Many appealing features make the course interactive, including the ability to see and hear via camera and microphone, messaging, document sharing, and small group discussion using breakouts. Anecdotal evidence implies a favorable response from distance students. Perceived benefits include increased motivation, preparation, and participation; collaboration and a sense of community; increased student exposure to new technology; and added convenience for students and faculty. The university may potentially benefit by attracting a wider pool of students. Also, the faculty member has a new technology in their toolkit that can potentially be used in a number of creative ways. A new format, however, poses some challenges, including faculty investment in learning the technology and environment, technology limitations and the potential for technical problems. We believe, however, that the benefits to student learning, as well as to the faculty member and university, outweigh the associated costs. Future research may explore whether this is the case.

\section{AUTHOR INFORMATION}

Dee Ann Ellingson, Ph.D., CPA, is Associate Professor of Accounting at the University of North Dakota. She received her Ph.D. in accounting from Virginia Tech. Her research is primarily in management accounting, accounting education, and marketing accounting services. E-mail: dellingson@business.und.edu (Corresponding author)

Matthew Notbohm is an Assistant Professor of Accounting at the University of North Dakota. He received his $\mathrm{Ph} . \mathrm{D}$ in accounting from Florida State University. His research interests include financial accounting, audit quality, and auditing regulation. E-mail: matthew.notbohm@business.und.edu

\section{REFERENCES}

1. Armstrong, A., Morris, M. \& Solomita, D. (2008). Applying Adult Learning Discussion and Coaching Pedagogies in a Blended Environment by Leveraging Virtual Classroom Using Adobe Connect. In C. Bonk et al. (Eds.), Proceedings of World Conference on E-Learning in Corporate, Government, Healthcare, and Higher Education 2008 (pp. 3594-3599). Chesapeake, VA: AACE. Retrieved from http://www.editlib.org/f/30185.

2. $\quad$ Bernard, R., Abrami, P., Lou, Y., Borokhovski, E., Wade, A., Wozney, L., Wallet, P., Fiset, M., Huang, B. (2004). How Does Distance Education Compare With Classroom Instruction? A Meta-Analysis of the Empirical Literature. Review of Educational Research. Fall, 74(3), 379-439.

3. Jackson, M., and Helms, M. (2008). Student Perceptions of Hybrid Courses: Measuring and Interpreting Quality. Journal of Education for Business. Sept/Oct, 84(1), 7-12.

4. Karabulut, A. \& Correia, A. (2008). Skype, Elluminate, Adobe Connect, Ivisit: A comparison of WebBased Video Conferencing Systems for Learning and Teaching. In K. McFerrin et al. (Eds.), Proceedings of Society for Information Technology \& Teacher Education International Conference 2008 (pp. 481-484). Chesapeake, VA: AACE. Retrieved from http://www.editlib.org/p/27212.

5. Khiewnavawongsa, S., Leong, R., and Schmidt, E. (2007). Real-Time Learning in a Distance Course. American Society for Engineering Education. Retrieved from http://icee.usm.edu/icee/conferences/asee2007/papers/1785 REAL TIME_LEARNING_IN_A DISTANC E COURSE.pdf

6. Offir, B., Lev, Y., and Bezalel, R. (2008). Surface and Deep Learning Processes in Distance Education: Synchronous Versus Asynchronous Systems. Computers \& Education. 51, 1172-1183.

7. Roblyer, M., Freeman, J., Donaldson, M., and Maddox, M. (2007). A Comparison of Outcomes of Virtual School Courses Offered in Synchronous and Asynchronous Formats. Internet and Higher Education. 10, 261-268.

8. Zabriskie, F., and McNabb, D. (2007). E-hancing the Master of Business Administration (MBA) Managerial Accounting Course. Journal of Education for Business. March, 82(4), 226-233. 
NOTES 